\title{
Several years in the life of a journal
}

\author{
Subhas K. Sikdar
}

Published online: 5 January 2014

(c) Springer-Verlag Berlin Heidelberg (outside the USA) 2014

Another year has passed and we are on the 16th year of publication of this journal. During the last 15 years we have learned much, came in contact with many colleagues who contributed to the journal with their original research articles, review papers, and personal reflections on issues of interest to us and our readers. We made many friends all over the world. A special mention must be made of the reviewers who generously contributed their professional time to assure the quality of science in the papers we published. We owe our collective gratitude to them for this professional courtesy. Last year we saw the retirement of two prominent volunteers: our co-founder and Co-Editor-in Chief, Prof. Ravi Jain, and our Editor for Europe, Prof. Neil Winterton. The Journal remains indebted to them for their selfless service. Both remain as emeritus to keep assisting us. And after many years of publishing Webwatch, we decided to discontinue this column with the thought that in this day and age of easy information retrieval from the web, this column probably is no longer necessary. We thank the editors, Dr. Teresa Mata and Dr. Antonio Martins for their dedicated service and timely alerts. Special issues are integral to our strategy of bringing in thematically focused manuscripts to our readers, and we will continue to publish them in the future. This year we also start a new column, E-Conversation. This issue will see the first of this series, an e-conversation with Prof. Roland Clift of the University of Surrey. We will continue such conversations with prominent researchers and thought leaders who have helped our technical understanding of sustainability and clean processing and who will freely share their thoughts and opinions on issues of great importance of the day. We would hope our readers will like this series.

We started with quarterly issues. Several years ago as submissions started increasing significantly we started publishing bimonthly issues. From 2014 we will publish eight issues per year. The submissions have increased so much recently that we don't have space for accommodating many publication worthy manuscripts. To cope with the steady increase in manuscript submission and still to maintain or improve publication time, we recruited two volunteers as regional editors: Prof. Jiri Klemes of the University of Pannonia, Hungary as the Editor for Europe, and Prof. Santanu Bandyopadhyay of the Indian Institute of Technology at Mumbai as an additional Editor for Asia. All these changes have been designed to improve quality, outreach, and impact of Clean Technologies and Environmental Policy. We keep listening to well-wishers who provide suggestions and implement them when we can.

This journal was started with the idea of promoting and showcasing technical advances in clean technologies that are based on the concepts of waste minimization, pollution prevention, and design for the environment. Sustainability from a technical viewpoint was not a theme that any journal embraced yet. Over the years we progressively recruited manuscripts based on sustainability and now it is the primary focus of articles we seek. Few in the technical field have made similar transition in their own lives and came to greatly influence the field than Prof. Roland Clift. Thus it is fitting that we start the E-Conversation with a dialogue with him. 